\title{
Effects of underlying morbidities on the occurrence of deaths in COVID-19 patients: A systematic review and meta-analysis
}

\author{
Md Mostaured Ali Khan ${ }^{1 *}$, \\ Md Nuruzzaman Khan², Md \\ Golam Mustagir ${ }^{1}$, Juwel Rana ${ }^{3}$, \\ Md Saiful Islam4, Md Iqbal \\ Kabir $^{4}$
}

\footnotetext{
${ }^{1}$ Department of Population Science and Human Resource Development, University of Rajshahi, Rajshahi, Bangladesh

${ }^{2}$ Department of Population Sciences, Jatiya Kabi Kazi Nazrul Islam University, Trishal, Mymensingh, Bangladesh

${ }^{3}$ Department of Public Health, North South University, Bashundhara, Dhaka, Bangladesh

${ }^{4}$ Planning, Monitoring and Research, Directorate General of Health Services (DGHS), Mohakhali, Dhaka, Bangladesh *Joint first authorship.
}

\section{Correspondence to:}

Md. Nuruzzaman Khan, MSc Lecturer

Department of Population Sciences Jatiya Kabi Kazi Nazrul Islam University Trishal

Mymensingh-2220

Bangladesh

sumonrupop@gmail.com
Background Coronavirus disease 2019 (COVID-19), the most hectic pandemic of the era, is increasing exponentially and taking thousands of lives worldwide. This study aimed to assess the prevalence of pre-existing comorbidities among COVID-19 patients and their mortality risks with each category of pre-existing comorbidity.

Methods To conduct this systematic review and meta-analysis, Medline, Web of Science, Scopus, and CINAHL databases were searched using pre-specified search strategies. Further searches were conducted using the reference list of the selected studies, renowned preprint servers (eg, medRxiv, bioRxiv, SSRN), and relevant journals' websites. Studies written in the English language included if those were conducted among COVID-19 patients with and without comorbidities and presented survivor vs non-survivor counts or hazard/odds of deaths or survivors with types of pre-existing comorbidities. Comorbidities reported in the selected studies were grouped into eight categories. The pooled likelihoods of deaths in each category were estimated using a fixed or random-effect model, based on the heterogeneity assessment. Publication bias was assessed by visual inspection of the funnel plot asymmetry and Egger's regression test. Trim and Fill method was used if there any publication bias was found.

Results A total of 41 studies included in this study comprised of 27670 samples. The most common pre-existing comorbidities in COVID-19 patients were hypertension (39.5\%), cardiovascular disease (12.4\%), and diabetes (25.2\%). The higher likelihood of deaths was found among COVID-19 patients who had pre-existing cardiovascular diseases (odds ratio $(O R)=3.42,95 \%$ confidence interval $(C I)=2.86$ 4.09), immune and metabolic disorders ( $\mathrm{OR}=2.46,95 \% \mathrm{CI}=2.03$ $2.85)$, respiratory diseases $(\mathrm{OR}=1.94,95 \% \mathrm{CI}=1.72-2.19)$, cerebrovascular diseases $(\mathrm{OR}=4.12,95 \% \mathrm{CI}=3.04-5.58)$, any types of cancers $(\mathrm{OR}=2.22,95 \% \mathrm{CI}=1.63-3.03)$, renal $(\mathrm{OR}=3.02,95 \% \mathrm{CI}=2.60-3.51)$, and liver diseases $(\mathrm{OR}=2.35,95 \% \mathrm{CI}=1.50-3.69)$.

Conclusions This study provides evidence that COVID-19 patients with pre-existing comorbidities had a higher likelihood of death. These findings could potentially help health care providers to sort out the most susceptible COVID-19 patients by comorbidities, take precautionary measures during hospitalization, assess susceptibility to death, and prioritize their treatment, which could potentially reduce the number of fatalities in COVID-19. 
The coronavirus disease 2019 (COVID-19) caused by the severe acute respiratory syndrome coronavirus 2 (SARS-CoV-2), a virus from the large coronavirus family, was first detected on December 31st, 2019 in Wuhan, China, and has now been deemed a global pandemic by the World Health Organization (WHO). The virus is highly transmissible (reproductive number: 1.6-6.5, doubling time: 6.4 to 7.4 days) [1], which is transmitted mainly through respiratory droplets (coughs or sneezes), close contact with the infected person [2,3], and touching surfaces or objects exposed to droplets [2,3]. As of July 27, 2020, 209 days since the virus was first detected, approximately 16.64 million people from 213 countries or territories have been infected with the virus [4,5]. Almost 0.66 million have already died [4], and about $1 \%$ of currently infected people are now in critical conditions [5]. To date, there is no specific medicine or vaccine for COVID-19; therefore, the majority of the affected countries are taking non-pharmaceutical interventions such as restriction in inhabitants' mobility, quarantine of suspected persons, isolation of infected persons, travel restrictions, and airport screening to reduce further infections $[1,6,7]$.

The virus is equally transmissible in all ages; however, people who are now in critical conditions or who have died were more likely to be in the elderly population and had one or more morbidities [8-11]. Commonly reported comorbidities among patients who died from COVID-19 were hypertension, diabetes, cardiovascular disease, and cerebrovascular disease [8,12-14]. Notably, these comorbidities are independent causes of millions of annual deaths globally, 17.9 million deaths from cardiovascular diseases, 9 million deaths from cancers, 3.9 million deaths from respiratory diseases, and 1.6 million deaths from diabetes, according to a WHO report from 2018 [15]. People with one or more of these morbidities usually have a poor immune system, which increases their susceptibility to being infected, to reach critical condition, and even die of a secondary disease like COVID-19 [1,12,16-19]. Precautionary measures following COVID-19 in patients with one or more morbidities could be potential ways to combat its adverse outcomes and severities. Thus, we need to identify morbidities that are potentially increasing the risks of mortality, which are still lacking. Moreover, studies conducted among COVID-19 patients are highly varied with reported comorbidities and their associated likelihoods of mortality $[8,10,20,21]$. Therefore, a systematic review and meta-analysis is important for summarizing and enlisting of comorbidities, which the secondary COVID-19 infection could potentially lead to adverse outcomes including deaths as well as to know the likelihoods of deaths for each morbidity. However, the few reviews that have been conducted up until now, failed to serve these purposes and were limited to the studies' settings and patients. For instance, detailed searches for this research explored four-reviews published, almost all were conducted based on evidences from China [14,22,23], which were limited to analyzing small scale hospital data [22], included only patients in severe condition [14,23] and failed to measure the effects of each comorbidity of death on COVID-19 [24]. No previous study has considered adequate global level evidence as well as the samples from all settings. To address these gaps, this study was conducted with two primary aims: (i) to summarize pre-existing comorbidities in patients with COVID-19, and (ii) to estimate the likelihood of mortality from COVID-19 with each category of pre-existing comorbidities. The study findings could help health care providers to take appropriate measures to control fatalities from this pandemic.

\section{METHODS}

This systematic review and meta-analysis was conducted by following the Preferred Reporting for Systematic Review and Meta-Analysis (PRISMA) consensus statement [25]. Studies relevant to the COVID-19 disease among people who were admitted to the hospital with one or more pre-existing comorbidities were included.

\section{Search strategy}

Four databases: Medline, Web of Science, Scopus, and CINAHL, were searched using pre-specified search strategies for each database and concluded on May 01, 2020. The search strategy consists of keywords on COVID-19 disease (COVID-19, 2019-nCoV, Coronavirus, SARS-CoV-2), pre-existing morbidity (comorbidity, morbidity), and patients' survival status (mortality, death, died) combined using the Boolean operators (AND, OR). Details of the search strategies are presented in Table S1-S4 in the Online Supplementary Document. Additional searches were conducted using the reference list of the selected studies, relevant journals' websites, and renowned preprint servers (medRxiv, bioRxiv, SSRN).

\section{Study selection criteria}

All peer-reviewed and preprint (not-peer-reviewed) studies met the pre-specified inclusion criteria were included in this study. 


\section{Inclusion criteria}

Studies were included if they met the following inclusion criteria: (i) conducted for the hospitalized patients infected with COVID-19 with or without pre-existing comorbidities, (ii) presented survivor and non-survivor counts following COVID-19 among patients with or without pre-existing morbidity or presented hazard/risk/odds ratio of deaths or survival following COVID-19 with the types of morbidities, and (iii) published in the English language. Studies without complete information but met our inclusion criteria were included in the narrative review.

\section{Exclusion criteria}

Studies were excluded if COVID-19 was reported among pregnant women or children (aged $<18$ years) because there are additional conditions or morbidities existing in these groups, such as pregnancy complications. We also excluded papers written in languages other than English. Additionally, we excluded review papers, correspondence, viewpoints, editorials, commentaries, and studies where no information related to previous morbidities were reported.

\section{Screening and review of articles}

All articles identified through the specified search strategy that were compiled and screened in Endnote version X9 (Thomson Reuters, Philadelphia, PA, USA). Two investigators (MMAK, MGM) independently screened the included articles based on inclusion and exclusion criteria. Initially, the titles and abstracts of the included studies were screened for a full-text review. Finally, the full-text of each of the selected studies were reviewed by the same investigators. Any conflict of interest faced by the investigators was reported to the senior authors (MNK and MIK) and solve based on the group discussion.

\section{Data extraction and quality assessment}

A data extraction form was designed, trialed, and modified to extract information from the selected studies. Two authors (MMAK and MGM) used the pre-designed form to extract information independently. The following information was extracted: study location, design, sample size, study population characteristics (eg, age, gender), and survivor vs non-survivor counts among COVID-19 patients with or without specific comorbidities. If available, the odds/risk/hazard ratio of deaths among COVID-19 patients with comorbidities were extracted against the types of morbidity. Disagreements reported in data extraction were reviewed and solved by the corresponding and senior authors (MNK and MIK). The Modified Newcastle-Ottawa scale, as part of the data extraction strategy, was used to assess the quality of selected studies [26]. The scale has been used commonly to assess the study quality included in the systematic review and meta-analysis [24,27,28].

\section{Statistical analysis}

One or more pre-existing comorbidities among COVID-19 patients reported in the selected studies were grouped into eight broad categories based on the type of comorbidities. These were cardiovascular system diseases (hypertension, cardiovascular disease, arrhythmia, heart failure), immune and metabolic disorders (diabetes, immunosuppression, autoimmune disease, immunodeficiency, metabolic disorder), respiratory system diseases (chronic lung diseases, Chronic Obstructive Pulmonary Disease (COPD), acute respiratory distress syndrome, tuberculosis, etc.), cancer (malignancy, cancer, and tumor), cerebrovascular diseases (cerebrovascular disease, peripheral vascular disease), renal system diseases (chronic kidney disease, urinary disease), liver system diseases (chronic liver disease, cirrhosis, hyperlipidemia, Hepatitis B, etc.), and gastrointestinal system diseases (chronic digestive disorder, gastrointestinal disease). The case definition of these comorbidities is presented in Table 1. The odds ratios (ORs) of deaths with 95\% confidence interval (95\% CI) for the people exposed to a particular category of comorbidity as compared to COVID-19 patients unexposed to another comorbidity was estimated from the extracted raw data or reported ORs. We first used the Haldane correction (add constant 0.5 to each cell) for the studies in which the sample included in the exposed or unexposed group was zero (such as all exposed patients died or vice versa) [29-31]. We then used either a fixed effect or random effect model to estimate ORs, selected based on heterogeneity assessment. When the test of heterogeneity ( $I^{2}$ statistics) was moderate ( $\left.50 \%-74 \%\right)$ or high $(\geq 75 \%)$, the pooled estimates of ORs were computed using the random-effects model [32]. Subgroup and meta-regression analyses were conducted for the groups where higher heterogeneity was reported. For this, pre-specified subgroups (types of morbidities, study country, study design, the mean age of the total sample, mean age of death sample) were used. Publication bias was assessed by visual inspection of the funnel plot asymmetry 
and Egger's regression test [33]. When evidence of publication bias was found, the Trim and Fill method of sensitivity analysis was used to adjust potentially missing studies, and the effect size was recalculated accordingly [34]. Stata software version 15.1 (StataCorp. LP, College Station, TX, USA) was used for all analyses.

Table 1. Case definitions for underlying diseases sought in this systematic review and meta-analysis

\begin{tabular}{|c|c|c|}
\hline Group & DiseASE & Case definition \\
\hline \multirow[t]{4}{*}{$\begin{array}{l}\text { Cardiovascular system } \\
\text { diseases }\end{array}$} & Hypertension & $\begin{array}{l}\text { Systolic blood pressure } \geq 140 \mathrm{~mm} \mathrm{Hg} \text { or diastolic blood pressure } \geq 90 \mathrm{~mm} \mathrm{Hg} \text { in two or more } \\
\text { consecutive visits. }\end{array}$ \\
\hline & Cardiovascular disease & A group of disorders of the heart and blood vessels \\
\hline & Arrythmia & $\begin{array}{l}\text { A disorder with the rate of the heartbeat (too slowl ( } \leq 60 \text { beats } / \mathrm{min}) \text {, too fast ( } 2100 \text { beats } / \mathrm{min} \text { ), } \\
\text { or irregular rhythm) }\end{array}$ \\
\hline & Heart failure & $\begin{array}{l}\text { A condition when the heart muscle is unable pump enough blood to meet the body's blood } \\
\text { and oxygen needs. }\end{array}$ \\
\hline \multirow[t]{6}{*}{$\begin{array}{l}\text { Immune and metabolic } \\
\text { disorders }\end{array}$} & Diabetes & $\begin{array}{l}\text { A disease that halts the body from producing the hormone insulin because of abnormal } \\
\text { carbohydrate metabolism and increased blood glucose levels. Blood glucose level }>200 \mathrm{mg} / \\
\mathrm{dL}(11.1 \mathrm{mmol} / \mathrm{L}) \text { after two hours of fasting indicates diabetes. }\end{array}$ \\
\hline & Immunosuppression & $\begin{array}{l}\text { Partial or complete suppression of the body's immune system to fight against the infections } \\
\text { and other diseases. }\end{array}$ \\
\hline & Autoimmune disease & A disorder in which the bodys immune system mistakenly attacks its own healthy tissues \\
\hline & Immunodeficiency & $\begin{array}{l}\text { The inability of the body to produce an immune response. In such condition the immune } \\
\text { system's ability to fight infectious diseases and cancer is impaired or completely absent. }\end{array}$ \\
\hline & Endocrine system disease & A hormonal imbalance in the body. It is determined through testing the blood and urine. \\
\hline & Metabolic disorder & A disruption of normal metabolic processes because of one or more missing enzyme. \\
\hline \multirow{7}{*}{$\begin{array}{l}\text { Respiratory system } \\
\text { diseases }\end{array}$} & Chronic lung disease & A disorder that affects the lungs and other parts of the respiratory system \\
\hline & $\begin{array}{l}\text { Chronic obstructive } \\
\text { pulmonary disease (COPD) }\end{array}$ & $\begin{array}{l}\text { A disorder that restricts normal breathing and measured through Tiffeneau-Pinelli index } \\
\text { (FEV1/FVC). The index value } 50 \text { or less refers moderate to severe stage of the COPD. }\end{array}$ \\
\hline & Asthma & $\begin{array}{l}\text { A disorder lead breathing difficulty. In such condition, the bronchial airways in the lungs } \\
\text { become narrowed and swollen and Tiffeneau-Pinelli index reduced to } 60 \text { or less for moderate } \\
\text { to severe stage of the Asthma. }\end{array}$ \\
\hline & $\begin{array}{l}\text { Acute respiratory distress } \\
\text { syndrome (ARDS) }\end{array}$ & A respiratory failure characterized by rapid start of extensive inflammation in the lungs. \\
\hline & Chronic bronchitis & $\begin{array}{l}\text { The swelling and irritation of the bronchial tubes that can lead to chronic cough and breathing } \\
\text { difficulties. }\end{array}$ \\
\hline & Tuberculosis & A disorder caused by a bacterial infection (name, Mycobacterium tuberculosis) in the lungs. \\
\hline & Pulmonary emphysema & $\begin{array}{l}\text { A chronic condition in which the alveoli may be collapsed, damaged, narrowed, overinflated, } \\
\text { or stretched. }\end{array}$ \\
\hline \multirow[t]{4}{*}{ Any types of cancer } & Malignancy & An abnormal cell division without control that can invade nearby tissues. \\
\hline & Cancer & A disorder in which any cells of the body begin to divide uncontrollably. \\
\hline & Tumor & Uncontrolled growth occurs in solid tissue like muscle or bone and could cause cancer. \\
\hline & Carcinoma & A specific type of cancer in epithelial tissue of the skin. \\
\hline \multirow{2}{*}{$\begin{array}{l}\text { Cerebrovascular } \\
\text { system diseases }\end{array}$} & Cerebrovascular disease & A disorder of the blood vessels and the arteries. \\
\hline & Peripheral vascular disease & $\begin{array}{l}\text { A disorder that makes the blood vessels narrow, block, or spasm outside of heart and brain. } \\
\text { Ankle/brachial index }(\mathrm{ABI}) \text { is used to measure this disorder where } \mathrm{ABI}>90 \text { is normal and } \\
\mathrm{ABI}<70 \text { indicates moderate to severe condition. }\end{array}$ \\
\hline \multirow[t]{2}{*}{ Renal system diseases } & Chronic kidney disease & $\begin{array}{l}\text { Glomerular filtration rate }(\mathrm{GFR})<60 \text { or serum creatinine }>1.1 \mathrm{mg} / \mathrm{dL} \text { for women and }>1.3 \mathrm{mg} \text { / } \\
\mathrm{dL} \text { for men refers to have chronic kidney disease. }\end{array}$ \\
\hline & Urinary disease & Includes infection in urinary tract, kidney stone, bladder control problems, prostate problems. \\
\hline \multirow[t]{6}{*}{ Liver system diseases } & Chronic liver disease & $\begin{array}{l}\text { Alanine aminotransferase test (ALT) }>40 \mathrm{U} / \mathrm{L} \text { and aspartate aminotransferase test (AST) }>40 \mathrm{U} / \mathrm{L} \\
\text { indicates chronic liver diseases }\end{array}$ \\
\hline & Cirrhosis & $\begin{array}{l}\text { A condition in which the liver fails to function properly due to long-term damage or liver } \\
\text { disease like hepatitis, fatty liver }\end{array}$ \\
\hline & Fatty liver disease & High fat builds up in liver. \\
\hline & Hepatitis B & Virus liver infection caused by hepatitis B virus. \\
\hline & Hyperlipidemia & $\begin{array}{l}\text { High levels of fats (lipids) in the blood. Cholesterol }>200 \mathrm{mg} / \mathrm{dL} \text {, and triglycerides }>150 \mathrm{mg} / \\
\mathrm{dL} \text { refers to hyperlipidemia }\end{array}$ \\
\hline & Inflammatory disease & $\begin{array}{l}\text { Erythrocyte sedimentation rate (ERS) }>22 \mathrm{~mm} / \mathrm{h} \text { for man and }>29 \mathrm{~mm} / \mathrm{h} \text { for women refers to } \\
\text { the presence of inflammatory disease }\end{array}$ \\
\hline \multirow[t]{2}{*}{$\begin{array}{l}\text { Gastrointestinal system } \\
\text { diseases }\end{array}$} & Chronic digestive disorder & $\begin{array}{l}\text { Disorders that occur in the digestive tract. Some common disorders include irritable bowel } \\
\text { syndrome, and lactose intolerance. }\end{array}$ \\
\hline & Gastrointestinal disease & $\begin{array}{l}\text { Diseases in gastrointestinal tract, namely the esophagus, large intestine, small intestine, and } \\
\text { rectum }\end{array}$ \\
\hline
\end{tabular}




\section{RESULTS}

A total of 247 articles were identified from the databases searched, and the additional 15 articles were identified by checking the reference list of the selected articles and the selected journals' websites (Figure 1). Around 1273 articles were also initially identified from the preprint servers. Of the selected articles, 1341 articles were excluded after screening titles and abstracts, leaving 114 articles for full-text review for possible inclusion in this study. Of these, 55 articles were excluded based on the inclusion and exclusion criteria for the study sample (eg, , excluded pregnant or children), and 11 articles were excluded for study types (eg, review papers, correspondence, viewpoints, editorials, commentaries), and six articles were excluded for entirely incomplete data. One article was excluded because it has been retracted by the published journal. A total of 41 articles were finally selected for this study; 35 articles were included in the meta-analysis, and the remaining six articles were synthesized narratively.

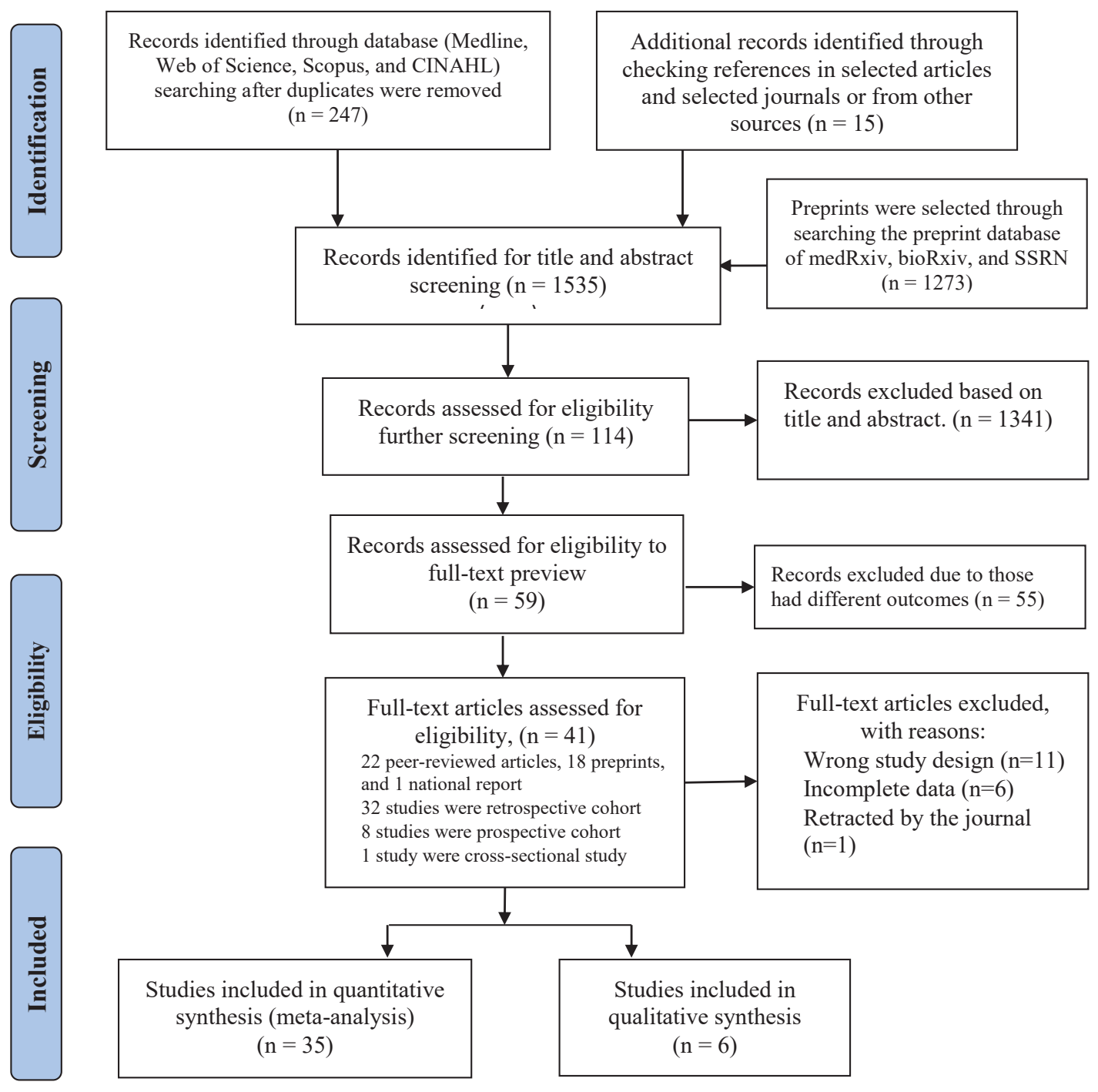

Figure 1. Schematic representation of studies included in the systematic review and meta-analysis using the PRISMA checklist and flow diagram.

\section{Study characteristics}

A summary of the 41 selected articles is represented in Table 2. A total of 22 of the selected 41 articles were published in peer-reviewed journals, and 18 articles were published in pre-print servers. One of the selected studies was a national report for Australia. The majority of these studies were retrospective in nature (32), along with eight prospective studies. The selected studies comprised of 27670 COVID-19 patients, 7558 (42.5\%) of them had pre-existing one or more comorbidities, $38.4 \%$ of patients had un- 
dergone critical care, and 4795 (17.3\%) of them died. Their average age was $60.9 \pm 7.9$ years, and $60.3 \%$ of them were male. The mean age at death was $70.4 \pm 4.9$ for the patients who died of COVID-19. A total of 35 selected studies presented death counts following COVID-19 among patients with or without one or more specific comorbidities. Four included studies (Du et al. [66], Zhang et al. [67], Kim et al. [68], and Yao et al. [69]) were conducted only for dead COVID-19 patients and reported the status of pre-existing comorbidities before their deaths. All studies were of moderate to high quality (Table S6-S7 in the Online Supplementary Document).

Table 2. Background characteristics of the selected studies and hospitalized sample $(n=27670)$

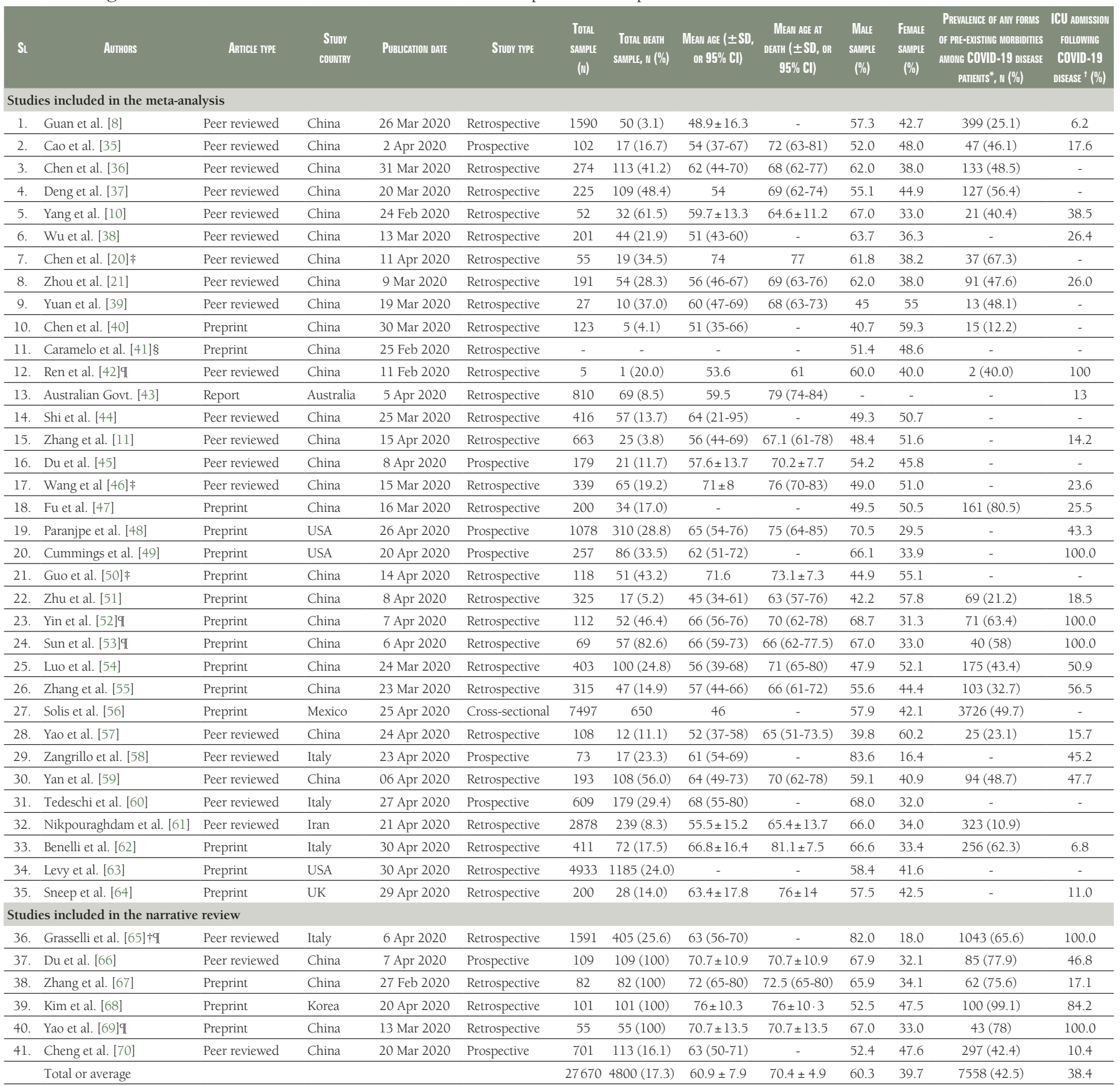

SD - standard deviation, CI - confidence interval

*Complete data available for 17794 patients, and missing sample had incomplete information or directly indicated the likelihood of mortality or did not report people count with any forms of existing comorbidities. Sample with missing value were excluded from percentage calculation.

†Included only the patients in ICU or in critical condition with or without pre-existing morbidities, and data was available for 10154 patients. ¥Included only aged or elderly people as sample.

\$Not included in total calculation as the study was a secondary data analysis.

IIncluded only the patients in ICU or in critical condition.

Sample included only death patients; study of Tedeschi et al [60] had all patients more than one comorbidities. 


\section{Prevalence of pre-existing morbidity among COVID-19 patients}

Distribution of the type of morbidity presented in Table 3. Approximately $39.5 \%$ of the total COVID-19 patients reported that they had hypertension, $25.2 \%$ had diabetes, $12.4 \%$ had cardiovascular disease, $5.8 \%$ had chronic lung disease, $2.6 \%$ had COPD, and 4.4\% had chronic kidney disease.

\section{Effects of pre-existing morbidity on deaths in COVID-19 patients}

The pooled ORs of deaths for each category of pre-existing comorbidities among COVID-19 patients, publication bias, and Trim and Fill estimates are presented in Table 4. COVID-19 patients with pre-existing cardiovascular disease were 3.42 times more likely to die $(\mathrm{OR}=3.42$, $95 \% \mathrm{CI}=2.86-4.09 ; I^{2}=81.2 \%$ ) than the patients who had no cardiovascular diseases. The odds of death among COVID-19 patients with immune and metabolic disorders were also found to be $246 \%$ higher $(\mathrm{OR}=2.46,95 \% \mathrm{CI}=2.03$ $2.85 ; I^{2}=64.8 \%$ ) than among COVID-19 patients without such disorders. The incidence of COVID-19 among people with respiratory diseases increases mortality risk around two times $\left(\mathrm{OR}=1.94,95 \% \mathrm{CI}=1.72-2.19 ; \mathrm{I}^{2}=75.7 \%\right)$ more than COVID-19 patients without respiratory system diseases. Similarly, we found higher mortality risk among COVID-19 patients who had pre-existing any types of cancers $(\mathrm{OR}=2.22$, 95\% CI $\left.=1.63-3.03, I^{2}=67.7 \%\right)$ and cerebrovascular system diseases $(\mathrm{OR}=4.12,95 \% \mathrm{CI}=3.04$ 5.58) more than their counterparts. Moreover, the incidence of COVID-19 among patients with pre-existing renal disease and chronic liver disease increased mortality risk by about three times $(\mathrm{OR}=3.02,95 \% \mathrm{CI}=2.60-3.51)$ more and one and half times $(\mathrm{OR}=2.35,95 \% \mathrm{CI}=1.50-3.69)$ more, respectively compared to the COVID-19 patients who did not have such comorbidities.

We found evidence of publication bias for the four categories of pre-existing comorbidities: cardiovascular diseases, cerebrovascular diseases, renal system diseases, and liver diseases (Figures S1A to S8A in the Online Supplementary Document). We then used Trim and Fill methods to impute the number of missing studies, which hypothetically imputed six studies for cardiovascular diseases, two studies for cerebrovascular diseases, four studies for renal diseases, and three studies for liver diseases. The pooled analysis, including these missing studies, showed almost similar results to the summary estimates presented earlier without these missing studies.
Table 3. Percentage distribution of comorbidities among patients reported in admission COVID-19 infection*

\begin{tabular}{|c|c|c|}
\hline Pre-Existing morbidities & $\begin{array}{l}\text { DIsTRABUTION OF } \\
\text { COMORBiDTIIES FOR } \\
\text { TOTAL PATIENTS }\end{array}$ & (\%)介 \\
\hline Cardiovascular system diseases & 9112 & 53.2 \\
\hline Hypertension & 6758 & 39.5 \\
\hline Cardiovascular disease $\dagger$ & 2128 & 12.4 \\
\hline Arrhythmia & 89 & 0.5 \\
\hline Heart failure & 137 & 0.8 \\
\hline Immune and metabolic disorders & 4581 & 26.8 \\
\hline Diabetes & 4318 & 25.2 \\
\hline
\end{tabular}

\begin{tabular}{lcc}
\hline Immunosuppression & 179 & 1.0 \\
\hline Endocrine system disease & 69 & 0.4 \\
\hline Autoimmune disease & 8 & 0.0 \\
\hline Immunodeficiency & 3 & 0.0 \\
\hline Metabolic disorder & 4 & 0.0 \\
\hline Respiratory system diseases & $\mathbf{1 8 4 9}$ & $\mathbf{1 0 . 8}$ \\
\hline Chronic lung disease & 991 & 5.8 \\
\hline Chronic obstructive pulmonary disease (COPD) & 449 & 2.6 \\
\hline Asthma & 376 & 2.2 \\
\hline Acute respiratory distress syndrome (ARDS) & 11 & 0.1 \\
\hline Chronic bronchitis & 10 & 0.1 \\
\hline Tuberculosis & 9 & 0.1 \\
\hline Pulmonary emphysema & 3 & 0.0 \\
\hline Any types of cancer & $\mathbf{2 4 8}$ & $\mathbf{1 . 4}$ \\
\hline Malignancy & 135 & 0.8 \\
\hline Cancer & 92 & 0.5 \\
\hline Tumor & 17 & 0.1 \\
\hline Carcinoma & 4 & 0.0 \\
\hline Cerebrovascular system diseases & $\mathbf{2 0 5}$ & $\mathbf{1 . 2}$ \\
\hline Cerebrovascular disease $¥$ & 196 & 1.1 \\
\hline Peripheral vascular disease & 9 & 0.1 \\
\hline Renal system diseases & 781 & 4.6 \\
\hline Chronic kidney disease & 760 & 4.4 \\
\hline Urinary disease & 21 & 0.1 \\
\hline Liver system diseases & $\mathbf{1 7 2}$ & $\mathbf{1 . 0}$ \\
\hline Chronic liver disease & 52 & 0.3 \\
\hline Cirrhosis & 33 & 0.2 \\
\hline Fatty liver disease & 15 & 0.1 \\
\hline Hepatitis B & 49 & 0.3 \\
\hline Hyperlipidemia & 17 & 0.1 \\
\hline Inflammatory disease & 6 & 0.0 \\
\hline Gastrointestinal system diseases & 61 & 0.4 \\
\hline Chronic digestive disorder & 21 & 0.1 \\
\hline Gastrointestinal disease & 40 & 0.2 \\
\hline Others§ & 109 & 0.6 \\
\hline Grand total & & 100 \\
\hline
\end{tabular}

*Patients with more than one comorbidity were missing. Calculated in column percentage format; One study (Caramelo et al. [41]) was excluded from prevalence calculation as the study had not reported frequency of comorbidities; Malnutrition and dementia was skipped from the analysis as we found only one patient (Yang et al. [10]).

$\dagger$ Included all types of cardiovascular diseases like coronary heart diseases or artery disease.

¥Included cerebral infarction.

§Anemia, bowel disease, tissue disease, etc.

TRepresentative for this study's included sample and could be different than the actual situation depending upon the counts in the included studies. 
Table 4. Summary effects of type of morbidity categories on death among patients infected with COVID-19 disease, publication bias, and Trim and Fill estimates

\begin{tabular}{|c|c|c|c|c|c|c|c|}
\hline \multirow[b]{2}{*}{ Characteristics } & \multirow[b]{2}{*}{$\begin{array}{l}\text { Number OF } \\
\text { StUDIES }\end{array}$} & \multirow[b]{2}{*}{$\begin{array}{l}\text { NUMBER OF TIMES } \\
\text { MORBIDITY REPORTED }\end{array}$} & \multicolumn{2}{|c|}{ SUMMARY ESTIMATES } & \multirow[b]{2}{*}{$\begin{array}{l}\text { Egger bias } \\
\text { test Pavalue }\end{array}$} & \multicolumn{2}{|c|}{ TRIM AND FIL ESTIMATES* } \\
\hline & & & OR (95\% CBI) & 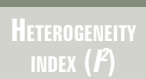 & & $\begin{array}{l}\text { Missing STUDIES } \\
\text { Nlo. }\end{array}$ & OR (9F\% 다) \\
\hline Cardiovascular system diseases & 32 & 60 & $3.42(2.86-4.09) \dagger$ & $81.2 \%$ & 0.001 & 6 & $2.93(2.46-3.49)$ \\
\hline Immune and metabolic disorders & 30 & 36 & $2.46(2.03-2.85) \dagger$ & $64.8 \%$ & 0.076 & 0 & $2.46(2.03-2.85)$ \\
\hline Respiratory system diseases & 27 & 32 & $1.94(1.72-2.19)$ 丰 & $75.7 \%$ & 0.053 & 0 & $1.94(1.72-2.19)$ \\
\hline Any types of cancer & 20 & 20 & $2.22(1.63-3.03) \neq$ & $67.7 \%$ & 0.891 & 0 & $2.22(1.63-3.03)$ \\
\hline Cerebrovascular system diseases & 15 & 16 & $4.12(3.04-5.58)$ 丰 & $25.7 \%$ & 0.048 & 2 & $3.94(2.92-5.31)$ \\
\hline Renal system diseases & 21 & 21 & $3.02(2.60-3.51) \neq$ & $56.0 \%$ & 0.024 & 4 & $2.86(2.47-3.32)$ \\
\hline Liver system diseases & 13 & 16 & $2.35(1.50-3.69)$ 丰 & $0.0 \%$ & 0.001 & 3 & $2.03(1.33-3.11)$ \\
\hline Gastrointestinal system diseases & 5 & 5 & $1.33(0.56-3.19)$ 丰 & $0.0 \%$ & 0.170 & 0 & $1.33(0.56-3.19)$ \\
\hline
\end{tabular}

OR - odds ratio, $\mathrm{CI}$ - confidence interval

* The trim-and-fill method simulates studies that are likely to be missing from the literature due to publication or other forms of bias. The trim-and-fill OR estimates what the pooled OR would be if these missing studies were included in the analysis.

$\uparrow$ Summary estimates were based on fixed-effects methods.

\$Summary estimates were based on random-effects methods. Person survived from COVID-19 infection is considered as reference category.

Evidence of higher deaths among COVID-19 patients with pre-existing comorbidities were also demonstrated in the narrative review (Table S5 in the Online Supplementary Document). In two of the three articles reviewed in this study, researchers reported that each of the patients who died following COVID-19 had pre-existing comorbidities, mostly had some type of cardiovascular diseases or immune and metabolic disorders $[66,67]$. Researchers in one study found around 38\% of the COVID-19 patients with hypertension died [65], and one study reported higher odds for deaths in kidney injury [70].

Table 5. Stratified analysis of the likelihood of death among patients with cardiovascular system diseases infected with COVID-19 diseases

\begin{tabular}{|c|c|c|c|}
\hline \multirow{2}{*}{ Characteristics } & \multirow{2}{*}{ PoOLED OR (95\% CI) } & \multicolumn{2}{|c|}{$P_{\text {-value }}$} \\
\hline & & HeterogenalIY & Meta-REGRESSION \\
\hline \multicolumn{4}{|l|}{ Type of diseases: } \\
\hline Cardiovascular diseases & $3.43(2.52-4.66)$ & $<0.01$ & 0.93 \\
\hline Hypertension & $3.36(2.64-4.28)$ & $<0.01$ & \\
\hline Heart failure & $4.72(3.19-6.97)$ & 0.643 & \\
\hline Arrhythmia & $3.89(2.51-6.02)++$ & NA & \\
\hline \multicolumn{4}{|l|}{ Study country: } \\
\hline Australia & $3.68(2.06-6.57)++$ & NA & $<0.01$ \\
\hline Italy & $3.82(2.90-5.02)$ & 0.368 & \\
\hline China & $4.24(3.30-5.44)$ & $<0.01$ & \\
\hline United State of America & $2.74(2.00-3.75)$ & $<0.01$ & \\
\hline Iran & $1.75(0.95-3.22)$ & 0.685 & \\
\hline UK & $2.73(1.17-6.35)++$ & NA & \\
\hline Mexico & $1.12(0.71-1.75)$ & $<0.05$ & \\
\hline \multicolumn{4}{|l|}{ Study design: } \\
\hline Cross-sectional & $1.12(0.71-1.75)$ & $<0.05$ & $<0.01$ \\
\hline Prospective cohort & $3.70(2.67-5.12)$ & $<0.01$ & \\
\hline Retrospective cohort & $3.58(2.93-4.37)$ & $<0.01$ & \\
\hline \multicolumn{4}{|l|}{ Adjustment factor: } \\
\hline Unadjusted & $2.79(1.60-4.84)$ & $<0.01$ & $<0.05$ \\
\hline Adjusted & $1.53(0.96-2.46)$ & $<0.01$ & \\
\hline \multicolumn{4}{|l|}{ Sample size: } \\
\hline$>1134$ & $2.33(1.53-3.55)$ & $<0.01$ & 0.091 \\
\hline$\leq 1134$ & $3.70(3.07-4.45)$ & $<0.01$ & \\
\hline \multicolumn{4}{|c|}{ Mean age of the total sample: } \\
\hline$\leq 60$ & $4.46(3.00-6.64)$ & $<0.01$ & 0.593 \\
\hline$>60$ & $3.00(2.48-3.62)$ & $<0.01$ & \\
\hline \multicolumn{4}{|l|}{ Mean age of death sample: } \\
\hline$\leq 70$ & $5.13(3.92-7.20)$ & $<0.01$ & $<0.01$ \\
\hline$>70$ & $2.54(2.06-3.12)$ & $<0.01$ & \\
\hline
\end{tabular}

\section{Stratified analysis}

We found evidence of high heterogeneity $\left(I^{2}>75 \%\right)$ for cardiovascular diseases $(81.2 \%)$ and respiratory diseases $(75.7 \%)$. To examine the sources of heterogeneity, we conducted stratified analysis across types of comorbidities, study design (cross-sectional vs retrospective cohort vs prospective cohort), sample size (divided based on the mean sample size of the included studies and classified as $\leq 1134,>1134$ ), age of the total sample (divided based on mean age and classified as $\leq 60$ years and $>60$ years), and age at death (divided based on mean age and classified as $\leq 70$ vs >70) (Table 5 and Table 6). We found odds of death varied across specific types of pre-existing comorbidities included to generate the cardiovascular diseases and respiratory diseases category. For instance, in the cardiovascular diseases category, the odds of mortality were higher for COVID-19 patients with pre-existing heart failure $(\mathrm{OR}=4.72,95 \% \mathrm{CI}=3.19-6.97)$, cardiovascular disease ( $\mathrm{OR}=3.43,95 \% \mathrm{CI}=2.52-4.66)$, hypertension ( $\mathrm{OR}=3.36,95 \% \mathrm{CI}=2.64-4.28)$, than for COVID-19 patients with pre-existing arrthythmia $(\mathrm{OR}=3.89,95 \% \mathrm{CI}=2.51-6.02)$. Similarly, in the respiratory diseases category, the odds of mortality were found higher for COVID-19 patients with pre-existing chronic lung disease $(\mathrm{OR}=3.34$, $95 \% \mathrm{CI}=2.15-5.18)$, and $\mathrm{COPD}(\mathrm{OR}=2.62,95 \%$ $\mathrm{CI}=1.48-4.64)$. 
Table 6. Stratified analysis of the likelihood of death among patients with respiratory system diseases infected with COVID-19 diseases

\begin{tabular}{|c|c|c|c|}
\hline \multirow{2}{*}{ Characteristics } & \multirow{2}{*}{ Pooled OR (95\% CI) } & \multicolumn{2}{|c|}{ P-value } \\
\hline & & HeterogenEIIY & MEAA-REGRESSION \\
\hline \multicolumn{4}{|l|}{ Type of diseases: } \\
\hline Chronic lung disease & $3.34(2.15-5.18)$ & $<0.01$ & 0.232 \\
\hline $\begin{array}{l}\text { Chronic obstructive } \\
\text { pulmonary disease (COPD) }\end{array}$ & $2.62(1.48-4.64)$ & $<0.01$ & \\
\hline Pulmonary emphysema & $4.69(0.41-52.97)++$ & NA & \\
\hline Chronic bronchitis & $1.53(0.41-5.68)++$ & NA & \\
\hline Asthma & $1.01(0.61-1.67)$ & 0.152 & \\
\hline \multicolumn{4}{|l|}{ Study country: } \\
\hline Australia & $4.56(2.47-8.44)_{++}$ & NA & 0.214 \\
\hline Italy & $1.54(0.73-3.25)$ & NA & \\
\hline China & $3.46(2.20-5.43)$ & $<0.01$ & \\
\hline United State of America & $2.11(1.26-3.52)$ & $<0.01$ & \\
\hline Iran & $2.16(1.05-4.45)++$ & NA & \\
\hline Mexico & $1.20(0.54-2.68)$ & $<0.01$ & \\
\hline \multicolumn{4}{|l|}{ Study design: } \\
\hline Cross-sectional & $1.20(0.54-2.68)$ & $<0.05$ & 0.221 \\
\hline Prospective cohort & $2.76(1.45-5.23)$ & $<0.01$ & \\
\hline Retrospective cohort & $2.98(2.00-4.44)$ & $<0.01$ & \\
\hline \multicolumn{4}{|l|}{ Adjustment factor: } \\
\hline Unadjusted & $2.79(1.60-4.84)$ & $<0.01$ & $<0.05$ \\
\hline Adjusted & $1.53(0.96-2.46)$ & $<0.01$ & \\
\hline \multicolumn{4}{|l|}{ Sample size: } \\
\hline$>1134$ & $1.88(1.14-3.09)$ & $<0.01$ & 0.161 \\
\hline$\leq 1134$ & $2.97(2.11-4.16)$ & $<0.01$ & \\
\hline \multicolumn{4}{|c|}{ Mean age of the total sample: } \\
\hline$\leq 60$ & $3.41(1.86-6.26)$ & $<0.01$ & 0.279 \\
\hline$>60$ & $2.32(2.63-3.29)$ & $<0.01$ & \\
\hline \multicolumn{4}{|l|}{ Mean age of death sample: } \\
\hline$\leq 70$ & $4.22(2.44-7.30)$ & 0.209 & 0.055 \\
\hline$>70$ & $2.16(1.57-2.99)$ & $<0.01$ & \\
\hline
\end{tabular}

\section{DISCUSSION}

This study aimed to summarize pre-existing comorbidities among COVID-19 patients, which increases their incidence of deaths and their corresponding likelihoods. A total of 42 studies were included that comprised 27670 samples, and $42.5 \%$ of them had any pre-existing comorbidities. The most frequently reported comorbidities were hypertension (39.5\%), diabetes (25.2\%), and cardiovascular disease (12.4\%). The likelihood of death was higher among COVID-19 patients who had comorbidities like cardiovascular diseases, cerebrovascular diseases, respiratory diseases, renal diseases, immune and metabolic disorders, hepatic diseases, and cancer. This evidence will guide physicians to take precautionary measures, which could reduce the number of fatalities following a secondary infection with COVID-19.

Among the total positive COVID-19 cases included in this systematic review, around $43 \%$ had one or more pre-existing comorbidities, mostly cardiovascular diseases, and immune and metabolic disorders. These underlying diseases are increasing the risk of death among COVID-19 patients. Recent reviews have confirmed that COVID-19 infection among patients with cardiovascular diseases, and immune and metabolic disorders, particularly, having hypertension and diabetes elevate the risk of infection severity, ICU admission, and the risk of death $[19,23]$. The underlying causes are that patients with these diseases are more likely to have a higher neutrophil-lymphocyte ratio [71,72], higher D-dimer level [73], and higher C-reactive protein

[74]. These are responsible for multiple organ failure [75,76], severe pneumonia, hypoxia, respiratory failure, myocardial damage, and circulatory failure [77], and these risks increase further if the patient is infected with COVID-19 [21,44,76,78] because of additional damage of myocardial cells [79,80]. Importantly, a similar higher risk of mortality was reported among the patients of cardiovascular diseases infected with the SARS-CoV and MERS-CoV [81,82]. These two diseases are considered as ancestors of the current COVID-19, which were reported in 2003 and 2012, respectively [44,81-83]. Evidence also validates that the occurrence of other viral infections like influenza, similar to COVID-19, could increase the risk of death if the patient has underlying cardiovascular diseases and diabetes [84].

Pooled likelihoods in this study provide evidence of higher deaths among COVID-19 patients who had pre-existing chronic respiratory diseases or any type of cancer- as found in other reviews [19,23]. The chronic respiratory diseases like COPD and asthma are well-established risk factors for pneumonia [85], which also increase the susceptibility to COVID-19 infection [86]. Once patients are infected with COVID-19, these underlying diseases further affect the patient's respiratory system and progress to severe hypoxemia [87]; therefore, the cumulative effects lead to the events of death $[77,86]$. Cancer patients are more likely to report a systemic immunosuppressive state and progress to severe clinical events in COVID-19, such as require intensive care (ICU) or death $[88,89]$. These underlying diseases have their own adverse consequences on the human body. Secondary infection of COVID-19, which could, therefore, increase serve clinical events as well as deaths among patients with these types of pre-existing comorbidities.

This study also suggests that patients with cerebrovascular, liver, and renal diseases are more vulnerable to mortality following the secondary incidence of COVID-19 than patients who do not have such diseases. The results are comparable to deaths among previously reported SARS patients [90]. Diseases such as car- 
dio-cerebrovascular diseases, liver damage, or renal diseases accelerate an abrupt loss of kidney function $[91,92]$, and tissue damage that causes hypoxia, shock, and rhabdomyolysis [70,93]. Importantly, these states also increase the occurrence of thrombocytopenia (reduced platelet counts in the blood) $[21,94]$. Together with COVID-19, these adverse effects could potentially elevate the risk of progression to a severe state or death of a COVID-19 patient. Moreover, elevated alanine aminotransferase (ALT) levels and reduced albumin levels are found to be associated with higher mortality in COVID-19 [21,94], which can be caused by chronic liver and kidney diseases [94-98].

\section{Strengths and limitations}

This study has several strengths and limitations that should be reported. To our knowledge, this is the first study of its kind that summarizes all morbidities among COVID-19 patients that lead to death using data from globally representative studies. Moreover, comorbidities reported among COVID-19 patients were classified into board groups based on their characteristics, and the likelihood of death was estimated separately for each group. This evidence will inform health care providers about the risk of death among COVID-19 patients with different groups of pre-existing comorbidities. Thus, they will be able to take precautionary measures early targeting to prevent deaths. However, this study reported the odds of death for COVID-19 patients with one pre-existing comorbidity only. Many COVID-19 patients may have multi-morbidities (COVID-19 with pre-existing two or more comorbidities), and they may have a higher risk of death. The studies included in this review considered each morbidity separately; for instance, if COVID-19 patients had both hypertension and diabetes, they were included in both groups. None of the included studies considered COVID-19 patients with two or more comorbidities together; therefore, we failed to provide the likelihood of deaths for higher risk patients. Moreover, the percentage distribution of morbidity among COVID-19 patients estimated in this study could be different from the actual situation depending upon the counts in the included studies. However, as we included all available studies conducted worldwide, therefore, any distortion is likely to be random. In addition, the likelihoods presented in this study were mostly unadjusted ( 31 of the 35 articles included) as they were calculated from the extracted raw data. This may overestimate or underestimate the actual likelihood of deaths in COVID-19 patients because age and other socio-demographic characteristics are potential confounders of their deaths, which should be adjusted for unbiased estimates. Despite these limitations, this study is unique and beneficial for health care providers to handle COVID-19 patients with pre-existing comorbidities.

\section{CONCLUSION}

About $43 \%$ of the sample included in this systematic review had one or more pre-existing comorbidities and had COVID-19 as a secondary infection. The most common pre-existing comorbidities were hypertension, diabetes, and cardiovascular disease. The likelihood of death was higher among COVID-19 patients who had pre-existing cardiovascular and cerebrovascular diseases, respiratory diseases, renal diseases, immune and metabolic disorders, liver diseases, and any types of cancer. These findings will help health care providers to sort COVID-19 patients by comorbidities, take precautionary measures during hospitalization, assess susceptibility to death, and prioritize their treatment. These could potentially reduce the number of fatalities from secondary infection with COVID-19 disease.

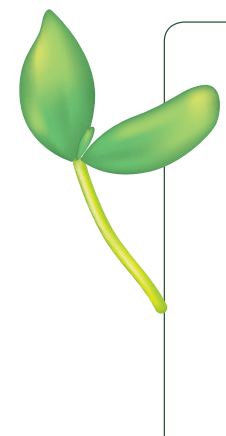

Acknowledgments: The authors are grateful to the authors of the paper included in this review. Authors thank the reviewers for their critical remarks improving the quality of this manuscript. Moreover, we would like to thank Taylor Harris and Dr Sinthia Mazumder for their comments on critical and clinical issues.

Funding: No fund was received for this study.

Authorship contributions: Conceptualization: MMAK, MNK, MIK. Research design: MMAK, MNK, and MIK. Data curation: MMAK and MGM. Analysis: MNK and MMAK. Draft preparation: MMAK, MNK, and MGM. Supervision: MNK and MIK. Critical review: MNK, JR, MIK, and MSI.

Competing interests: The authors completed the ICMJE Unified Competing Interest form (available upon request from the corresponding author), and declare no conflicts of interest.

\section{Additional material}

Online Supplementary Document 
1 Park M, Cook AR, Lim JT, Sun Y, Dickens BL. A Systematic Review of COVID-19 Epidemiology Based on Current Evidence. J Clin Med. 2020;9:967. Medline:32244365 doi:10.3390/jcm9040967

2 Centers for Disease Control and Prevention. Coronavirus Disease 2019 (COVID-19), 2020. Available: https://www.cdc. gov/coronavirus/2019-ncov/prepare/transmission.html. Accessed: 20 March 2020.

3 Chan JF, Yuan S, Kok KH, To KK, Chu H, Yang J, et al. A familial cluster of pneumonia associated with the 2019 novel coronavirus indicating person-to-person transmission: a study of a family cluster. Lancet. 2020;395:514-23. Medline:31986261 doi:10.1016/S0140-6736(20)30154-9

4 World Health Organization. WHO Coronavirus Disease (COVID-19) Dashboard, 2020. Available: https://covid19.who. int/. Accessed: 27 July 2020.

5 Worldmeter. COVID-19 Coronavirus Pandemic (Real time database), 2020. Available: https://www.worldometers.info/ coronavirus/. Accessed: 27 July 2020.

$6 \mathrm{WHO}$. Non-pharmaceutical public health measures for mitigating the risk and impact of epidemic and pandemic influenza: annex: report of systematic literature reviews. 2019, World Health Organization: Geneva, Switzerland.

7 Cowling BJ, Ali ST, Ng TW, Tsang TK, Li JC, Fong MW, et al. Impact assessment of non-pharmaceutical interventions against coronavirus disease 2019 and influenza in Hong Kong: an observational study. Lancet Public Health. 2020;5:e27988. Medline:32311320 doi:10.1016/S2468-2667(20)30090-6

8 Guan WJ, Liang WH, Zhao Y, Liang HR, Chen ZS, Li YM, et al. Comorbidity and its impact on 1590 patients with Covid-19 in China: A Nationwide Analysis. Eur Respir J. 2020;55:2000547. Medline:32217650 doi:10.1183/13993003.00547-2020

9 Jain V, Yuan J. Predictive symptoms and comorbidities for severe COVID-19 and intensive care unit admission: a systematic review and meta-analysis. Int J Public Health. 2020; Online ahead of print. Medline:32451563 doi:10.1007/ s00038-020-01390-7

10 Yang X, Yu Y, Xu J, Shu H, Xia J, Liu H, et al. Clinical course and outcomes of critically ill patients with SARS-CoV-2 pneumonia in Wuhan, China: a single-centered, retrospective, observational study. Lancet Respir Med. 2020;8:475-81. Medline:32105632 doi:10.1016/\$2213-2600(20)30079-5

11 Zhang J, Wang X, Jia X, Li J, Hu K, Chen G, et al. Risk factors for disease severity, unimprovement, and mortality in COVID-19 patients in Wuhan, China. Clin Microbiol Infect. 2020;26:767-72. Medline:32304745 doi:10.1016/j. cmi.2020.04.012

12 Siordia JA. Epidemiology and clinical features of COVID-19: A review of current literature. J Clin Virol. 2020;127:104357. Medline:32305884 doi:10.1016/j.jcv.2020.104357

13 Huang C, Wang Y, Li X, Ren L, Zhao J, Hu Y, et al. Clinical features of patients infected with 2019 novel coronavirus in Wuhan, China. Lancet. 2020;395:497-506. Medline:31986264 doi:10.1016/S0140-6736(20)30183-5

14 Yang J, Zheng Y, Gou X, Pu K, Chen Z, Guo Q, et al. Prevalence of comorbidities in the novel Wuhan coronavirus (COVID-19) infection: a systematic review and meta-analysis. Int J Infect Dis. 2020;94:91-5. Medline:32173574 doi: 10.1016/j.ijid.2020.03.017

15 WHO. Noncommunicable diseases. 2018, World Health Organization: Geneva, Switzerland.

16 Henry BM, Lippi G. Chronic kidney disease is associated with severe coronavirus disease 2019 (COVID-19) infection. Int Urol Nephrol. 2020;52:1193-4. Medline:32222883 doi:10.1007/s11255-020-02451-9

17 Madjid M, Safavi-Naeini P, Solomon SD, Vardeny O. Potential effects of coronaviruses on the cardiovascular system: a review. JAMA Cardiol. 2020. Online ahead of print. Medline:32219363 doi:10.1001/jamacardio.2020.1286

18 Ruan Q, Yang K, Wang W, Jiang L, Song J. Clinical predictors of mortality due to COVID-19 based on an analysis of data of 150 patients from Wuhan, China. Intensive Care Med. 2020;46:846-8. Medline:32125452 doi:10.1007/s00134-020-05991-X

19 Yang J, Zheng Y, Gou X, Pu K, Chen Z, Guo Q, et al. Prevalence of comorbidities and its effects in patients infected with SARS-CoV-2: a systematic review and meta-analysis. Int J Infect Dis. 2020;94:91-5. Medline:32173574 doi:10.1016/j. ijid.2020.03.017

20 Chen T, Dai Z, Mo P, Li X, Ma Z, Song S, et al. Clinical characteristics and outcomes of older patients with coronavirus disease 2019 (COVID-19) in Wuhan, China (2019): a single-centered, retrospective study. J Gerontol A Biol Sci Med Sci. 2020. Online ahead of print. Medline:32279081 doi:10.1093/gerona/glaa089

21 Zhou F, Yu T, Du R, Fan G, Liu Y, Liu Z, et al. Clinical course and risk factors for mortality of adult inpatients with COVID-19 in Wuhan, China: a retrospective cohort study. Lancet. 2020;395:1054-62. Medline:32171076 doi:10.1016/ S0140-6736(20)30566-3

22 Emami A, Javanmardi F, Pirbonyeh N, Akbari A. Prevalence of underlying diseases in hospitalized patients with COVID-19: a systematic review and meta-analysis. Arch Acad Emerg Med. 2020;8:e35. Medline:32232218

23 Jain V, Yuan J-M. Predictive symptoms and comorbidities for severe COVID-19 and intensive care unit admission: a systematic review and meta-analysis. Int J Public Health. 2020;•••:1-14. Medline:32451563 doi:10.1007/s00038-02001390-7

24 Liu H, Chen S, Liu M, Nie H, Lu H. Comorbid chronic diseases are strongly correlated with disease severity among COVID-19 patients: a systematic review and meta-analysis. Aging Dis. 2020;11:668-78. Medline:32489711 doi:10.14336/ AD.2020.0502

25 Moher D, Liberati A, Tetzlaff J, Altman DG. Preferred reporting items for systematic reviews and meta-analyses: the PRISMA statement. PLoS Med. 2009;6:e1000097. Medline:19621072 doi:10.1371/journal.pmed.1000097

26 Khan MN, Harris ML, Shifti DM, Laar AS, Loxton D. Effects of unintended pregnancy on maternal healthcare services utilization in low- and lower-middle-income countries: systematic review and meta-analysis. Int J Public Health. 2019;64:743-54. Medline:31041453 doi:10.1007/s00038-019-01238-9 
27 Lo CK-L, Mertz D, Loeb M. Newcastle-Ottawa Scale: comparing reviewers' to authors' assessments. BMC Med Res Methodol. 2014;14:45. Medline:24690082 doi:10.1186/1471-2288-14-45

28 Peterson J, Welch V, Losos M, Tugwell P. The Newcastle-Ottawa scale (NOS) for assessing the quality of nonrandomised studies in meta-analyses. 2011. Available: http://www.ohri.ca/programs/clinical_epidemiology/oxford.asp. Accessed: 15 June 2020.

29 Valenzuela C. 2 solutions for estimating odds ratios with zeros. Rev Med Chil. 1993;121:1441-4. Medline:8085071

30 Liu D, Liu RY, Xie M. Exact meta-analysis approach for discrete data and its application to $2 \times 2$ tables with rare events. J Am Stat Assoc. 2014;109:1450-65. Medline:25620825 doi:10.1080/01621459.2014.946318

31 Papastergiou P, Mouchtouri V, Pinaka O, Katsiaflaka A, Rachiotis G, Hadjichristodoulou C. Elevated bathing-associated disease risks despite certified water quality: a cohort study. Int J Environ Res Public Health. 2012;9:1548-65. Medline:22754456 doi:10.3390/ijerph9051548

32 Higgins JPT, Thompson SG, Deeks JJ, Altman DG. Measuring inconsistency in meta-analyses. BMJ. 2003;327:557-60. Medline:12958120 doi:10.1136/bmj.327.7414.557

33 Egger M, Smith GD, Schneider M, Minder C. Bias in meta-analysis detected by a simple, graphical test. BMJ. 1997;315:62934. Medline:9310563 doi:10.1136/bmj.315.7109.629

34 Duval S, Tweedie R. Trim and fill: a simple funnel plot-based method of testing and adjusting for publication bias in meta-analysis. Biometrics. 2000;56:455-63. Medline:10877304 doi:10.1111/j.0006-341X.2000.00455.x

35 Cao J, Tu WJ, Cheng W, Yu L, Liu YK, Hu X, et al. Clinical Features and Short-term Outcomes of 102 Patients with Corona Virus Disease 2019 in Wuhan, China. Clin Infect Dis. 2020. Online ahead of print. Medline:32239127 doi:10.1093/ $\mathrm{cid} / \mathrm{ciaa} 243$

36 Chen T, Wu D, Chen H, Yan W, Yang D, Chen G, et al. Clinical characteristics of 113 deceased patients with coronavirus disease 2019: retrospective study. BMJ. 2020;368:m1091. Medline:32217556 doi:10.1136/bmj.m1091

37 Deng Y, Liu W, Liu K, Fang YY, Shang J, Zhou L, et al. Clinical characteristics of fatal and recovered cases of coronavirus disease 2019 (COVID-19) in Wuhan, China: a retrospective study. Chin Med J (Engl). 2020;133:1261-7. Medline:32209890 doi:10.1097/CM9.0000000000000824

$38 \mathrm{Wu}$ C, Chen X, Cai Y, Xia J, Zhou X, Xu S, et al. risk factors associated with acute respiratory distress syndrome and death in patients with Coronavirus Disease 2019 pneumonia in Wuhan, China. JAMA Intern Med. 2020;180:1-11. Medline:32167524 doi:10.1001/jamainternmed.2020.0994

39 Yuan M, Yin W, Tao Z, Tan W, Hu Y. Association of radiologic findings with mortality of patients infected with 2019 novel coronavirus in Wuhan, China. PLoS One. 2020;15:e0230548. Medline:32191764 doi:10.1371/journal.pone.0230548

40 Chen X, Jiang Q, Ma Z, Ling J, Hu W, Cao Q, et al. Clinical characteristics of hospitalized patients with SARS-CoV-2 and hepatitis B virus co-infection. medRxiv. 2020. Available: https://www.medrxiv.org/content/10.1101/2020.03.23.20040733v2. Accessed: 15 June 2020.

41 Caramelo F, Ferreira N, and Oliveiros B. Estimation of risk factors for COVID-19 mortality - preliminary results. medRxiv. 2020. Available: https://www.medrxiv.org/content/10.1101/2020.02.24.20027268v1. Accessed: 15 June 2020.

42 Ren LL, Wang YM, Wu ZQ, Xiang ZC, Guo L, Xu T, et al. Identification of a novel coronavirus causing severe pneumonia in human: a descriptive study. Chin Med J (Engl). 2020;133:1015-24. Medline:32004165 doi:10.1097/ CM9.0000000000000722

43 Govt. A, COVID-19, Australia: Epidemiology Report 12: Reporting week in Communicable diseases intelligence. 2020, Department of Health, Australian Government.

44 Shi S, Qin M, Shen B, Cai Y, Liu T, Yang F, et al. Association of Cardiac Injury With Mortality in Hospitalized Patients With COVID-19 in Wuhan, China. JAMA Cardiol. 2020;e200950. Online ahead of print. Medline:32211816 doi:10.1001/ jamacardio.2020.0950

45 Du R-H, Liang L-R, Yang C-Q, Wang W, Cao T-Z, Li M, et al. Predictors of Mortality for Patients with COVID-19 Pneumonia Caused by SARS-CoV-2: A Prospective Cohort Study. Eur Respir J. 2020;55:2000524. Medline:32269088 doi:10.1183/13993003.00524-2020

46 Wang L, He W, Yu X, Hu D, Bao M, Liu H, et al. Coronavirus disease 2019 in elderly patients: Characteristics and prognostic factors based on 4-week follow-up. J Infect. 2020;80:639-45. Medline:32240670 doi:10.1016/j.jinf.2020.03.019

47 Fu L, Fei J, Xiang H-X, Xiang Y, Tan Z-X, Li M-D, et al. Influence factors of death risk among COVID-19 patients in Wuhan, China: a hospital-based case-cohort study. medRxiv. 2020. Available: https://www.medrxiv.org/ content/10.1101/2020.03.13.20035329v1. Accessed: 15 June 2020.

48 Paranjpe I, Russak A, De Freitas JK, Lala A, Miotto R, Vaid A, et al. Clinical characteristics of hospitalized covid-19 patients in New York City. medRxiv. 2020. Available: https://www.medrxiv.org/content/10.1101/2020.04.19.20062117v2. Accessed: 15 June 2020.

49 Cummings MJ, Baldwin MR, Abrams D, Jacobson SD, Meyer BJ, Balough EM, et al. Epidemiology, clinical course, and outcomes of critically ill adults with COVID-19 in New York City: a prospective cohort study. medRxiv. 2020. Available: https://www.medrxiv.org/content/10.1101/2020.04.15.20067157v1. Accessed: 15 June 2020.

50 Guo T-M, Tong Y, Chen J, Huang L, Cheng B, Zhoue J. Clinical features predicting mortality risk in older patients with COVID-19. SSRN. 2020. Available: https://papers.ssrn.com/sol3/papers.cfm?abstract_id=3569846. Accessed: 15 June 2020.

51 Zhu Q, Zhao S, Lai X, Zhao J, Guo D, Gan L, et al. Dose-response association between risk factors and incidence of COVID-19 in 325 hospitalized patients: a multicenter retrospective cohort study. SSRN. 2020. Available: https://papers. ssrn.com/sol3/Papers.cfm?abstract_id=3562478. Accessed: 15 June 2020. 
52 Yin Y, Zhou S, Zhang X, Li Z, Liu X, Jiang C, et al. Critically ill patients with COVID-19 in China: a multicenter retrospective observational study. SSRN. 2020. Available: https://papers.ssrn.com/sol3/papers.cfm?abstract_id=3562469. Accessed: 15 June 2020

53 Sun X, Wang J, Liu Z, Zhou X, Yan X-w, Li T, et al. Characteristics of patients with covid-19 pneumonia admitted to the intensive care unit and predictors of mortality in Wuhan, China: A single-centered retrospective cohort study. SSRN. 2020. Available: https://papers.ssrn.com/sol3/papers.cfm?abstract_id=3559629. Accessed: 15 June 2020.

54 Luo XM, Zhou W, Xia H, Yang W, Yan X, Wang B, et al. Characteristics of SARS-CoV-2 infected patients with clinical outcome during epidemic ongoing outbreak in Wuhan, China. SSRN. 2020. Available: https://papers.ssrn.com/sol3/ papers.cfm?abstract_id=3552812. Accessed: 15 June 2020.

55 Zhang S, Guo M, Duan L, Wu F, Wang Z, Xu J, et al. Short term outcomes and risk factors for mortality in patients with COVID-19 in Wuhan, China: a retrospective study. SSRN. 2020.Available: https://papers.ssrn.com/sol3/papers. cfm?abstract_id=3551390. Accessed: 15 June 2020.

56 Solís P and Carreňo H. COVID-19 fatality and comorbidity risk factors among confirmed patients in Mexico. medRxiv. 2020. Available: https://www.medrxiv.org/content/10.1101/2020.04.21.20074591v1. Accessed: 15 June 2020.

57 Yao Q, Wang P, Wang X, Qie G, Meng M, Tong X, et al. A retrospective study of risk factors for severe SARS-Cov-2 infections in hospitalized adult patients. Pol Arch Intern Med. 2020;130. Published online April 24, 2020. doi:10.20452/ pamw. 15312

58 Zangrillo A, Beretta L, Scandroglio AM, Monti G, Fominskiy E, Colombo S, et al. Characteristics, treatment, outcomes and cause of death of invasively ventilated patients with COVID-19 ARDS in Milan, Italy. Crit Care Resusc. 2020. Online ahead of print. Medline:32353223

59 Yan Y, Yang Y, Wang F, Ren H, Zhang S, Shi X, et al. Clinical characteristics and outcomes of patients with severe covid-19 with diabetes. BMJ Open Diabetes Res Care. 2020;8:e001343. Medline:32345579 doi:10.1136/bmjdrc-2020-001343

60 Tedeschi S, Giannella M, Bartoletti M, Trapani F, Tadolini M, Borghi C, et al. Clinical impact of renin-angiotensin system inhibitors on in-hospital mortality of patients with hypertension hospitalized for COVID-19. Clin Infect Dis. 2020. Online ahead of print. Medline:32339215 doi:10.1093/cid/ciaa492

61 Nikpouraghdam M, Jalali Farahani A, Alishiri G, Heydari S, Ebrahimnia M, Samadinia H, et al. Epidemiological characteristics of coronavirus disease 2019 (COVID-19) patients in IRAN: A single center study. J Clin Virol. 2020;127:104378. Medline:32353762 doi:10.1016/j.jcv.2020.104378

62 Benelli G, Buscarini E, Canetta C, La Piana G, Merli G, Scartabellati A, et al. SARS-COV-2 comorbidity network and outcome in hospitalized patients in Crema, Italy. medRxiv. 2020. Available: https://www.medrxiv.org/ content/10.1101/2020.04.14.20053090v2. Accessed: 15 June 2020.

63 Levy TJ, Richardson S, Coppa K, Barnaby DP, McGinn T, Becker LB, et al. Estimating survival of hospitalized COVID-19 patients from admission information. medRxiv. 2020. Available: https://www.medrxiv.org/ content/10.1101/2020.04.22.20075416v3. Accessed: 15 June 2020.

64 Sneep R, Cantle F, Brookes A, Jina R, Williams S, Galloway J, et al. Early epidemiological and clinical analysis of the first 200 patients with COVID-19 admitted via the emergency department in Kings College Hospital, London: a retrospective cohort study. SSRN. 2020. Available: https://ssrn.com/abstract=3576791. Accessed: 15 June 2020.

65 Grasselli G, Zangrillo A, Zanella A, Antonelli M, Cabrini L, Castelli A, et al. Baseline Characteristics and Outcomes of 1591 Patients Infected With SARS-CoV-2 Admitted to ICUs of the Lombardy Region, Italy. JAMA. 2020;323:1574-81. Medline:32250385 doi:10.1001/jama.2020.5394

66 Du RH, Liu LM, Yin W, Wang W, Guan LL, Yuan ML, et al. Hospitalization and critical care of 109 decedents with COVID-19 Pneumonia in Wuhan, China. Ann Am Thorac Soc. 2020;17:839-46. Medline:32255382 doi:10.1513/ AnnalsATS.202003-2250C

67 Zhang B, Zhou X, Qiu Y, Feng F, Feng J, Jia Y, et al. Clinical characteristics of 82 death cases with COVID-19. medRxiv. 2020. Available: https://www.medrxiv.org/content/10.1101/2020.02.26.20028191v1. Accessed: 15 June 2020.

68 Kim T, Park O, Yoo H, Ahn S, Jo J, Kim JW, et al. Epidemiological and clinical characteristics of early 101 deceased patients in the coronavirus disease-19 (COVID-19) outbreak in Republic of Korea. SSRN. 2020. Available: https://papers. ssrn.com/sol3/papers.cfm?abstract_id=3571538. Accessed: 15 June 2020.

69 Yao T, Gao Y, Cui Q, Shen J, Peng B, Chen Y, et al. Clinical characteristics of 55 cases of deaths with COVID-19 pneumonia in Wuhan, China: retrospective case series. SSRN. 2020. Available: https://papers.ssrn.com/sol3/papers.cfm?abstract_ id=3564376. Accessed: 15 June 2020..

70 Cheng Y, Luo R, Wang K, Zhang M, Wang Z, Dong L, et al. Kidney disease is associated with in-hospital death of patients with COVID-19. Kidney Int. 2020;97:829-38. Medline:32247631 doi:10.1016/j.kint.2020.03.005

71 Angkananard T, Anothaisintawee T, McEvoy M, Attia J, Thakkinstian A. Neutrophil Lymphocyte Ratio and Cardiovascular Disease Risk: A Systematic Review and Meta-Analysis. BioMed Res Int. 2018;2018:2703518. Medline:30534554 doi:10.1155/2018/2703518

72 Mertoglu C, Gunay M. Neutrophil-Lymphocyte ratio and Platelet-Lymphocyte ratio as useful predictive markers of prediabetes and diabetes mellitus. Diabetes Metab Syndr. 2017;11:S127-31. Medline:28017281 doi:10.1016/j. dsx.2016.12.021

73 Nwose EU, Richards RS, Jelinek HF, Kerr PG. D-dimer identifies stages in the progression of diabetes mellitus from family history of diabetes to cardiovascular complications. Pathology. 2007;39:252-7. Medline:17454757 doi:10.1080/00313020701230658 
74 Bisoendial RJ, Boekholdt SM, Vergeer M, Stroes ESG, Kastelein JJP. C-reactive protein is a mediator of cardiovascular disease. Eur Heart J. 2010;31:2087-91. Medline:20685682 doi:10.1093/eurheartj/ehq238

75 Wang D, Hu B, Hu C, Zhu F, Liu X, Zhang J, et al. Clinical characteristics of 138 hospitalized patients with 2019 novel coronavirus-infected pneumonia in Wuhan, China. JAMA. 2020;323:1061-9. Medline:32031570 doi:10.1001/ jama.2020.1585

76 Chen N, Zhou M, Dong X, Qu J, Gong F, Han Y, et al. Epidemiological and clinical characteristics of 99 cases of 2019 novel coronavirus pneumonia in Wuhan, China: a descriptive study. Lancet. 2020;395:507-13. Medline:32007143 doi:10.1016/S0140-6736(20)30211-7

77 Ruan Q, Yang K, Wang W, Jiang L, Song J. Clinical predictors of mortality due to COVID-19 based on an analysis of data of 150 patients from Wuhan, China. Intensive Care Med. 2020;46:846-8. Medline:32125452 doi:10.1007/s00134020-05991-X

78 Liu Y, Du X, Chen J, Jin Y, Peng L, Wang HHX, et al. Neutrophil-to-lymphocyte ratio as an independent risk factor for mortality in hospitalized patients with COVID-19. J Infect. 2020;81:e6-12. Medline:32283162 doi:10.1016/j. jinf.2020.04.002

79 Guo T, Fan Y, Chen M, Wu X, Zhang L, He T, et al. cardiovascular implications of fatal outcomes of patients with coronavirus disease 2019 (COVID-19). JAMA Cardiol. 2020. Online ahead of pring. Medline:32219356 doi:10.1001/ jamacardio.2020.1017

80 Clerkin Kevin J, Fried Justin A, Raikhelkar J, Sayer G, Griffin Jan M, Masoumi A, et al. Coronavirus disease 2019 (COVID-19) and cardiovascular disease. Circulation. 2020;141:1648-55.

81 Alhogbani T. Acute myocarditis associated with novel Middle East respiratory syndrome coronavirus. Ann Saudi Med. 2016;36:78-80. Medline:26922692 doi:10.5144/0256-4947.2016.78

82 Oudit GY, Kassiri Z, Jiang C, Liu PP, Poutanen SM, Penninger JM, et al. SARS-coronavirus modulation of myocardial ACE2 expression and inflammation in patients with SARS. Eur J Clin Invest. 2009;39:618-25. Medline:19453650 doi:10.1111/j.1365-2362.2009.02153.x

83 Guo T, Fan Y, Chen M, Wu X, Zhang L, He T, et al. Cardiovascular implications of fatal outcomes of patients with coronavirus disease 2019 (COVID-19). JAMA Cardiol. 2020. Online ahead of print. Medline:32219356 doi:10.1001/ jamacardio.2020.1017

84 Martínez A, Soldevila N, Romero-Tamarit A, Torner N, Godoy P, Rius C, et al. Risk factors associated with severe outcomes in adult hospitalized patients according to influenza type and subtype. PLoS One. 2019;14:e0210353. Medline:30633778 doi:10.1371/journal.pone.0210353

85 Restrepo MI, Mortensen EM, Pugh JA, Anzueto A. COPD is associated with increased mortality in patients with communityacquired pneumonia. Eur Respir J. 2006;28:346-51. Medline:16611653 doi:10.1183/09031936.06.00131905

86 Halpin DMG, Faner R, Sibila O, Badia JR, Agusti A. Do chronic respiratory diseases or their treatment affect the risk of SARS-CoV-2 infection? Lancet Respir Med. 2020;8:436-8. Medline:32251625 doi:10.1016/S2213-2600(20)30167-3

87 Lippi G, Henry BM. Chronic obstructive pulmonary disease is associated with severe coronavirus disease 2019 (COVID-19). Respir Med. 2020;167:105941. Medline:32421537 doi:10.1016/j.rmed.2020.105941

88 Liang W, Guan W, Chen R, Wang W, Li J, Xu K, et al. Cancer patients in SARS-CoV-2 infection: a nationwide analysis in China. Lancet Oncol. 2020;21:335-7. Medline:32066541 doi:10.1016/S1470-2045(20)30096-6

89 Hanna TP, Evans GA, Booth CM. Cancer, COVID-19 and the precautionary principle: prioritizing treatment during a global pandemic. Nat Rev Clin Oncol. 2020;17:268-70. Medline:32242095 doi:10.1038/s41571-020-0362-6

90 Tsang KW, Ho PL, Ooi GC, Yee WK, Wang T, Chan-Yeung M, et al. A cluster of cases of severe acute respiratory syndrome in Hong Kong. N Engl J Med. 2003;348:1977-85. Medline:12671062 doi:10.1056/NEJMoa030666

91 Vanmassenhove J, Kielstein J, Jörres A, Van Biesen W. Management of patients at risk of acute kidney injury. Lancet. 2017;389:2139-51. Medline:28561005 doi:10.1016/S0140-6736(17)31329-6

92 Lau WL, Huisa BN, Fisher M. the cerebrovascular-chronic kidney disease connection: perspectives and mechanisms. Transl Stroke Res. 2017;8:67-76. Medline:27628245 doi:10.1007/s12975-016-0499-x

93 Tisoncik JR, Korth MJ, Simmons CP, Farrar J, Martin TR, Katze MG. Into the eye of the cytokine storm. Microbiol Mol Biol Rev. 2012;76:16-32. Medline:22390970 doi:10.1128/MMBR.05015-11

94 Boettler T, Newsome PN, Mondelli MU, Maticic M, Cordero E, Cornberg M, et al. Care of patients with liver disease during the COVID-19 pandemic: EASL-ESCMID position paper. JHEP Rep. 2020;2:100113. Medline:32289115 doi:10.1016/j. jhepr.2020.100113

95 Afdhal N, McHutchison J, Brown R, Jacobson I, Manns M, Poordad F, et al. Thrombocytopenia associated with chronic liver disease. J Hepatol. 2008;48:1000-7. Medline:18433919 doi:10.1016/j.jhep.2008.03.009

96 Dorgalaleh A, Mahmudi M, Tabibian S, Khatib ZK, Tamaddon GH, Moghaddam ES, et al. Anemia and thrombocytopenia in acute and chronic renal failure. Int J Hematol Oncol Stem Cell Res. 2013;7:34-9. Medline:24505541

97 Lang J, Katz R, Ix JH, Gutierrez OM, Peralta CA, Parikh CR, et al. Association of serum albumin levels with kidney function decline and incident chronic kidney disease in elders. Nephrol Dial Transplant. 2018;33:986-92. Medline:28992097 doi:10.1093/ndt/gfx229

98 Oh RC, Hustead TR, Ali SM, Pantsari MW. Mildly elevated liver transaminase levels: causes and evaluation. Am Fam Physician. 2017;96:709-15. Medline:29431403 